\title{
Hannah Arendt e o filósofo como storyteller
}

\author{
Hannah Arendt and the philosopher as storyteller
}

DOI: $10.20873 / \mathrm{rpv} 6 \mathrm{n} 2-99$

\author{
Odilio Alves Aguiar \\ Orcid: https://orcid.org/0000-0002-7767-1932 \\ Email: odilio@ufc.br
}

\begin{abstract}
Resumo
0 artigo enseja discutir o estilo arendtiano de filosofar. A nossa hipótese de trabalho é simples. Para nós, Arendt elaborou além da pergunta 0 que é a Política, e talvez por causa dela, também a pergunta 0 que é a Filosofia, o que é o pensar. Na nossa perspectiva, três imagens usadas por Arendt podem ser entendidas como metáforas para compreendermos o que é Filosofia. São elas: o espectador, o storyteller e o pária. No presente artigo iremos abordar a figura do storyteller como metáfora do filosofar em Arendt.
\end{abstract}

\section{Palavras-chave}

Arendt. Filosofia. Pensamento. Imagens. Storyteller.

\begin{abstract}
The article aims to discuss the Arendtian style of philosophizing. Our working hypothesis is simple to enunciate: for us, Arendt elaborated, in addition to the question What is Politics, and perhaps because of it, also the question What is Philosophy, what is thinking. In our perspective, three images used by Arendt can be understood as metaphors to understand what Philosophy is. They are: the spectator, the storyteller and the pariah. In this article we will approach the figure of the storyteller as a metaphor for philosophizing in Arendt
\end{abstract}

\section{Keywords}

Arendt. Philosophy. Thinking. Images. Storyteller.

Existem vários tipos de filósofos, muitos são os estilos de filosofar que foram se constituindo ao longo da História da Filosofia. Tem prevalecido, porém, o modo filosófico-teológico que se ocupa com o absoluto e as causas últimas do real ou o filósofo-matemático que exige do 
filosofar coerência e legitimidade axiomática. Na nossa exposição, vamos abordar uma visão de filósofo que oscila entre o historiador e o literata. Para isso nos aproximamos da reflexão arendtiana. A nossa hipótese de trabalho é simples de enunciar: para nós, Arendt elaborou além da pergunta 0 que é a Política, e talvez por causa dela, também a pergunta 0 que é a Filosofia, o que é o pensar. Na nossa perspectiva, três imagens usadas por Arendt podem ser entendidas como metáforas para compreendermos o que é Filosofia. São elas: o espectador, o storyteller $e$ $o$ pária. Enfatizo que são apenas imagens, metáforas, pistas, para não incorrermos no risco de entender o filosofar, em Arendt, de forma substancialista. Como metáforas, apenas insinuam e indicam o filosofar como uma espécie de lugar vazio que qualquer ser humano poderá ocupar conforme a posição e o modo de se interessar pela vida. Iniciemos pela figura do contador de histórias (storyteller).

A exploração do tema do filósofo como contador de história (storyteller) nos remete ao modo como Arendt escreveu e apresentou as grandes questões nas suas obras. É a escritura arendtiana mesma que está em jogo, o seu estilo. Esse estilo não é algo desvinculado dos problemas que ela traz à baila. Lisa Disch, em Hannah Arendt and the Limits of Philosophy, explora um insight presente num pequeno-grande artigo de Seyla Benhabib, intitulado "Hannah Arendt and the Redemptive Power of Narrative", no qual a Autora argumenta a propósito da narrativa como método adequado para lidar com a história em Arendt. 0 que pretendemos realizar aqui é um alargamento do que Benhabib e Disch propõem e mostrar como o próprio pensamento, isto é, a filosofia, possui uma dimensão "narracional" em Arendt.

O totalitarismo, nas palavras de Bruehl, provocou uma verdadeira "diáspora mental", uma falência completa dos conceitos, doutrinas e verdades da tradição. Numa situação como a dos governos totalitários o passado não tem autoridade sobre o presente e os fundamentos tradicionais de compreensão foram estilhaçados. Em face dessa falência geral dos fios que viabilizavam a compreensão dos acontecimentos, Arendt vai entender que a única saída para quem persiste no exercício da compreensão do mundo, na sua caótica contingência, é tornar-se narrador (storyteller). Quando o pensamento e a realidade se apartam, segundo Arendt, contar 
"histórias" (stories) é o meio mais apropriado de remeter-nos à realidade que os nossos conceitos abstratos não são mais adequados para penetrar e iluminar. A vulnerabilidade dos universais no contexto totalitário acentua as feições de uma situação cuja saída para a reflexão é alinhar-se à narrativa. Numa situação de completa "ideologização" da ciência e da filosofia, os conceitos deixam de manifestar o sentido inerente ao real e se transformam em meio de se proteger e fabricar a realidade. Em face disso, não adianta buscar o sentido no fio proveniente da tradição. 0 pensamento se vê, assim, na tarefa difícil de encontrar o sentido sem poder contar com os padrões universais estabelecidos como tais pelo passado. 0 filósofo tende a se tornar um narrador (storyteller), pois não adianta mais partir de uma universalidade dada aprioristicamente, uma vez que o sentido só emergirá na medida em que o pensamento se debruçar sobre os acontecimentos. Reconstituir, na imaginação, acontecimentos passa a ser a condição para o pensamento apreender a significação neles presentes. A “herança sem testamento" como a situação do pensamento no mundo contemporâneo, como diz Arendt em Entre o Passado e o Futuro $_{\llcorner}$obriga a filosofia a se reconciliar com a existência e a buscar a sua significação no seu âmbito mesmo e não em outro mundo ou numa legalidade ou conhecimento do curso histórico no seu todo.

Pelo menos, foi assim com Arendt. 0 totalitarismo a levou a se tornar uma contadora de histórias (storyteller). Vale dizer, ao tentar escrever sobre a experiência totalitária, Arendt se viu diante de um "problema epistemológico", pois essa experiência não podia ser explicada, não se enquadrava nos conceitos tradicionais, não podia ser entendida como culminação de um processo, como desenvolvimento de uma única causa encontrável no passado. Não era o passado que poderia iluminar e explicar o seu aparecimento. Não se tratava de uma evolução, de algo que podia ser deduzido de uma causa antecedente. A saída que Arendt encontrou foi narrar a experiência. Nessa prática verificou que, ao contrário, o próprio acontecimento ilumina o que no passado pode a ele estar relacionado. Origens do Totalitarismo encerra a narrativa de movimentos políticos contemporâneos que se alçaram à cena do poder e que mantinham a pretensão de domínio total. Como diz Arendt, numa polêmica com Voegelin sobre o método do livro há pouco referido: "eu não escrevi uma história do totalitarismo, mas uma análise em termos 
históricos dos elementos que se cristalizaram no totalitarismo" (ARENDT, 1993a, p. 403). 0 totalitarismo não possui uma história, não estava contido potencialmente num evento do passado, mas cristalizou elementos de várias proveniências, como o imperialismo, antissemitismo, crise dos estados nacionais e do eurocentrismo.

Em Compreensão e Política, artigo que publicou logo após o livro sobre o totalitarismo, Arendt se depara com o "problema epistemológico" por ele posto e aponta a narrativa como saída. A narrativa presente em Origens do Totalitarismo mostra que não se trata de mera descrição dos fatos, mas de um modo de pensá-los. Talvez isso tenha gerado várias incompreensões. Exigiam do livro algo que a Autora não pretendia dele: que fosse um livro de ciência histórica. Isaiah Berlin e Voegelin, entre outros, reclamam do procedimento arendtiano. 0 primeiro queixa-se de várias inexatidões factuais e o segundo questiona o amplo uso de metáforas no livro. Eles não entendiam que Arendt na verdade estava realizando um "exercício de pensamento", visava, antes de tudo, a incitar à compreensão e que isso exige muitas vezes o recurso da metáfora, isto é, o que conta não é a reprodução, o espelhamento descritivo do que ocorreu, mas a fidelidade total às experiências geradoras dos pensamentos em pauta e isso eles não podiam questionar na obra arendtiana. 0 que eles não entenderam é que Origens do Totalitarismo não é para ser lido como livro de ciência, mas de filosofia. Nele, a Autora está pensando e não apenas reconstituindo os fatos. Não se trata de um pensamento que pensa os universais, mas que procura encontrar nos trágicos eventos da primeira metade do século algum sentido, algo que possa iluminá-los.

Se for verdade, como diz Heidegger, que todo grande pensador passa a vida pensando um único pensamento, poderíamos dizer que todo o pensamento de Arendt é motivado, no fundo, pela tentativa de decifrar, compreender os massacres administrativos, como foi possível o aparecimento no interior da cultura ocidental esse tipo de realidade e qual o antídoto para isso. Nesse aspecto, poderíamos dizer que Arendt é uma narradora do mundo contemporâneo. Em todos os seus escritos, é possível perceber que ela está perseguindo uma luz que ilumine o que o homem está fazendo na atualidade, o que pretende com as suas instituições e seus modos de vida. 
A posição da ação, a pluralidade humana como sendo a sua condição, no pensamento de Arendt, não pensada a partir de um padrão, fez com que essa Autora compreendesse o seu trabalho como uma narrativa do "grande jogo do mundo". Contar a "história" é a única maneira de a ação permanecer na memória dos homens e dos feitos e palavras humanas adquirirem dignidade por parte do pensamento. Ao se transformar numa storyteller, Arendt rejeita a posição de um ponto de vista arquimediano como uma postura apropriada para o filosofar e nos insere no entrecho de um pensamento "narracional" como o seu modus philosophandi. Na figura do filósofo como narrador há um crescimento da importância do juízo para se compreender o filosofar em Arendt. 0 pensamento entendido como juízo, ligado às circunstâncias mundanas, libera o filósofo da tarefa de tematizar o absoluto, os princípios constitutivos de tudo (ser - ponto de vista arquimediano), e abre a vereda para a compreensão dos caóticos acontecimentos mundanos, isto é, viabiliza a transformação do filósofo em contador de história.

O pensamento "narracional" é o meio que o pensador encontra para lidar com os eventos quando os cânones da historiografia, da metafísica e do pensamento político perderam a capacidade de iluminar o que está acontecendo. Na ausência de padrões confiáveis, passa-se a invocar as próprias experiências como base da análise. Poderíamos dizer que Arendt desenvolve uma concepção de filosofia como narração (storytelling), a habilidade de reter as experiências faz do pensador um contador de histórias. Essa abertura do pensamento para as experiências é que está na origem da ideia de um "pensar apaixonado", no qual a vida do espírito deita suas realizações mais importantes não se dedicando às questões últimas, metafísicas, como nos antigos, mas no desinteressado prazer de julgar os acontecimentos. Nesse aspecto, o filósofo não está na companhia dos deuses, segue um percurso amplamente trilhado pelos historiadores, poetas e narradores.

Há uma estreita relação entre a atividade de narrar uma história e o processo circular do pensamento. O narrador convida o ouvinte ou leitor a penetrar nas várias facetas de um acontecimento, deixa livre, não fecha. Cabe ao ouvinte/leitor tomar a decisão quanto à posição que adotará. Como o pensamento, a narração não é retilínea e convida cada um a recontar a história. Aliás, Arendt sempre dizia que cada geração tem que recontar o passado. Da mesma 
forma é o pensamento. Pensar para Arendt não se trata de uma herdade, é um processo sem fim, remete sempre a um repensar. Uma nova perspectiva vislumbrada pode acarretar o repensamento em torno de algo. 0 filósofo não é o guardador de plantão da verdade. Ele incita cada um a buscá-la por conta própria.

Ao conceber o filósofo como um contador de histórias, Arendt encontra o modo de superar o abismo entre filosofia e política, o modelo abstrato de imparcialidade que predominou na tradição filosófica ocidental, o qual se pautava na exigência da retirada absoluta, na assunção de um ponto de vista completamente externo aos assuntos humanos como condição para o filosofar, o que produzia o sacrifício dos assuntos humanos na sua dimensão contingencial. Na verdade, o pensamento "narracional" é uma forma de se contrapor ao modo fundacional de pensar, no qual os dilemas, paradoxos e conflitos da existência humana são submetidos a um critério único, abstrato e externo, que vem tomado como medida eficaz na solução de tais problemas, em função do seu completo distanciamento deles.

A perspectiva arquimediana é conduzida pelo interesse em mover os assuntos humanos a partir do ponto fixo da teoria. A perspectiva conceitual, denuncia Arendt, ambiciona o controle sobre a existência. Nela, a filosofia deixou de ser interrogação, de incitar cada um a pensar por conta própria, para apresentar padrões capazes de legitimar comportamentos. É forte o interesse normativista nesse tipo de filosofar (cf. MORAES, 1993). A filosofia, assim entendida, não está interessada em despertar as pessoas para o pensamento, como na maiêutica, mas para um determinado tipo de ação, a qual estaria respaldada num padrão racional universal. Nessa perspectiva, há como que apenas uma solução e caminho para os conflitos humanos. A teoria é concebida como solução e não questionamento.

Ao contrário, o pensamento "narracional" tem como modelo a imparcialidade de Tucídides, pois se trata de uma imparcialidade situada e não abstrata. 0 narrador apresenta os dilemas e paradoxos e leva os outros a tomar posição por conta própria. Os problemas éticos, por exemplo, nessa perspectiva, não são subsumíveis a um valor único. Os dilemas são mais bem apresentados, quando se conta a respeito deles uma história do que quando são submetidos a 
um critério de estilo arquimediano. 0 pensamento "narracional" não ambiciona levar a um comportamento $\mathrm{x}$, propor-se como autoridade legitimante de um determinado comportamento, mas simplesmente provocar o pensamento das pessoas.

Essa imparcialidade situada, encontramos exposta numa forma bastante compreensível, quando Arendt se refere a Lessing, no discurso feito na cidade de Hamburgo, por ocasião do recebimento de um prêmio e que foi editado em Homens em Tempos Sombrios. Escreve Arendt: "um componente de grandeza de Lessing foi o fato de nunca permitir que a suposta objetividade o levasse a perder de vista a relação real com o mundo e o estatuto real das coisas ou homens do mundo que elogiava ou atacava" (ARENDT, 1987, p. 15). 0 pensamento "narracional" não trata uma situação complexa reduzindo-a a um conceito, dissolvendo e sacrificando seus componentes, suas "vozes" internas, mas aposta na sua reconstituição pela imaginação com a forma de encontrar significação própria. A imaginação joga um papel central na concepção arendtiana de imparcialidade situada.

Ao contrário da imparcialidade abstrata, na qual se recorre à faculdade da razão para se encontrar um padrão normativo e legitimante, a imparcialidade situada enseja reconstituir a experiência como forma de encontrar a sua significação. Nesse aspecto, o pensamento "narracional" possui uma dimensão poética, pois não parte de uma verdade universal e manifesta o sentido inerente às experiências particulares. Não há uma verdade ou legalidade universal presidindo as particulares experiências dos homens, e, por isso, para Arendt, apenas a sua reconstituição imaginativa pode fazer emergir a sua razão de ser. A base desse pensamento é a experiência e não o raciocínio acerca do universal. Isso, porém, não equivale a dizer que em Arendt haja uma espécie de Ursprungphilosophie, como se ela defendesse a ideia de uma origem pura, intocada para o pensar, livre das incrustações conceituais, ideológicas etc. Não é disso que se trata e sim da reconciliação entre significação e aparência, generalidade e particularidade, filosofia e política, pensamento e contingência.

É a valorização da memória no pensamento "narracional" que viabiliza essa reconciliação. Nesse ponto, vemos que a forte influência de Agostinho se faz sentir no pensamento arendtiano, bem como do seu amigo e filósofo Walter Benjamin. Através desses pensadores, Arendt 
vislumbrou um modo de o pensamento se reconciliar com a contingência, com o initium (Agostinho) e com os fragmentos (Benjamin). Isto é, através deles, Arendt aprendeu a possibilidade de encarar os assuntos humanos sem o recurso da causalidade ou de uma teleologia universal. O pensamento narrativo encontra a significação dos acontecimentos neles mesmos sem precisar recorrer a um fluxo contínuo e metafísico para a vida.

Através da imaginação, o contador de histórias consegue manter o que a teoria quer dissolver, uma vez que sua pretensão não é determinar um caminho, apresentar a única solução, nem controlar o percurso histórico, mas reter, formar e contar uma história a partir dos indeterminados acontecimentos humanos. É isso que possibilita uma efetiva reconciliação entre o pensamento e as coisas humanas. 0 pensamento "narracional" não está preocupado com a história do ser, mas, sim, em encontrar significação nas contingentes ações humanas. Vale dizer, o homem, suas circunstâncias e ações, não é submetido a um padrão externo, conceitual, ideológico ou científico. O pensamento "narracional" encontra sentido na descontinuidade, nos fragmentos, na aparência (existência) e se contrapõe à solução teórico-causal-teleológica que só vê sentido na continuidade e no universal. 0 forte da postura narrativa é justamente a valorização que faz das palavras, ações e feitos humanos na sua particularidade. Somente a imaginação pode socorrer o pensamento na sua reconciliação com essas dimensões, sem ela o pensamento fica vazio. Retendo-as, recheia-se de vida.

Essa abertura para a contingência pode reconciliar filosofia e política, uma vez que a política e o mundo humano como tal é uma esfera em que não há qualquer determinação a priori. Qualquer tentativa de concebê-lo em termos de determinação, implica querer controlálo, burocratizá-lo. É esse o sentido que achamos estar presente, quando Arendt faz a defesa intransigente da verdade factual no artigo Verdade e Política. Não se trata de defender uma pureza interpretativa ou descritiva, mas sim de intransigentemente chamar atenção para o fato de que os assuntos humanos são contingentes, frágeis, e que querer dar-lhes uma sustentação completamente segura é um perigo, seja ela teórica ou político-ideológica. Isso significa eliminar a dimensão mundana do mundo e acreditar que os homens são incapazes, por eles mesmos, de dotar sua vida de significação. Por assim proceder, as teorias são enquadradoras, nelas os 
sentidos não podem ser provenientes das palavras e ações humanas, mas sim dos pensamentos e posições arquimedianas.

Para Arendt, a filosofia tradicional, ontológica e sistemática, preocupada com o ser na sua universalidade, deduzia a política do sistema. Isso fez com que nossa Autora dela se distanciasse e encontrasse outra forma de pensar a política na sua contingência e mesmo assim permanecer um "pensamento pensante", não cognitivo. Essa dificuldade do filósofo tradicional de lidar com a ação, Arendt resolve com a figura do filósofo-narrador. Em A Condição Humana na qual prevalece como tom geral a compreensão da ação e da política como esferas completamente frágeis, contingentes, Arendt vai defender o argumento de que somente a história (story) e, portanto, o filósofo-narrador, pode remediar a futilidade da ação e do discurso (ARENDT, 2010, p. 194-205). É essa capacidade do filósofo-narrador de reter a ação na sua contingência que o torna central para se solucionar a cisão entre pensamento e ação na tradição filosófica ocidental (cf. RICOEUR, 1995, 60-66). Nas Lições, sobre Kant, nas quais a relação entre filosofia e política é o tema central, o espectador é apresentado como a solução para esse conflito, justamente porque ao se tornar um narador, reúne e preserva, através da imaginação (go visiting), a ação humana na sua dimensão mundano-contingencial.

Por último, é interessante frisar o pensamento "narracional" e a posição do storyteller como uma postura crítica. A filosofia de linhagem arquimediana construiu como modelo de criticidade o distanciamento completo da sensibilidade e isso foi assimilado pela tradição como a exigência básica para um pensamento ser considerado crítico. Em razão da hegemonia desse racionalismo exacerbado, a arte, literatura, poesia e todas as formas de expressões do pensamento relacionadas a situações particulares foram concebidas como acríticas. Somente a ancoragem conceitual, na filosofia tradicional, é capaz de liberar o pensamento do dogmatismo e da ingenuidade.

Como, então, conjugar base experiencial e criticidade? Isto é, é possível afirmar que o pensamento "narracional" (storytelling) é capaz de conciliar as duas dimensões? Seguindo as pegadas arendtianas desde o texto Compreensão e Política a A Vida do Espírito, sem esquecermos de mencionar o precioso artigo sobre história, em Entre o Passado e o Futuro, onde ela 
diferencia objetividade e imparcialidade, sem dúvida alguma é obviamente possível e necessário reivindicar criticidade para o pensamento experiencial. A filosofia como narração (storytelling) está para além do fundacionalismo e do subjetivismo, do objetivismo e do relativismo. Para que isso ocorra, é necessário, em primeiro lugar, diferenciar a compreensão de Arendt do pensamento como narração das concepções clássicas do narrar relacionadas a uma compreensão da narrativa comprometida com a ideia de tradição, como veículo de transmissão da história e da identidade dos povos, possuidora de efeitos disciplinadores. Arendt também se diferencia do entendimento da narração como voz dos marginalizados (marginal voice) em contraposição à narrativa oficial, universal, consensual etc. Nessas concepções, os produtos da narração serviriam como apoio para a autoridade ou prescreveriam comportamentos.

Se observarmos com atenção, mesmo o maior inspirador de Arendt nesse setor, Walter Benjamin, não escapou a essa compreensão. Para ele, a narração possui uma dimensão utilitária, sempre propõe "um ensinamento moral, uma sugestão prática”, "conselhos” (cf. BENJAMIN, 1993, p. 200) e grande maioria dos seus intérpretes entende a narrativa como voz dos marginalizados. Em Arendt, o pensamento narracional não é comprometido como a defesa de uma tradição ou de um grupo específico, não intenta conduzir ou legitimar uma ação. Storytelling, é antes de tudo, encontrar e trazer à luz o sentido nas indeterminadas e "caóticas" experiências humanas. É a partir daí que podemos compreender o seu elogio a Denesen, que afirma que todos os sofrimentos humanos podem ser suportados quando fazemos deles uma história (story) ou contamos uma história a seu respeito, frase tomada como epigrama do capítulo sobre ação, em A Condição Humana.

O pensar narrativo é crítico porque ele enseja (pensa Arendt inspirada em Benjamin), antes de qualquer coisa a troca de experiências, o storyteller transforma as experiências brutas num produto sólido e único: a "história” (story), e para isso é exigida atenção, postura de espectador e é reclamado o questionamento dos hábitos que levam sempre à exclusão dos processos reflexivos (cf. ARENDT, 1987, p. 113-176). Uma Storytelling, o mergulho na espessura da experiência, só é possível com a ativação da capacidade de associar e rememorar, isto é, do pensar (ROUANET, 1990, p. 62-65). O storyteller, como o flâneur, se distancia do passante massificado 
através da capacidade de narrar que ele ainda mantém viva. A memória recuperada pelo storyteller não está relacionada à transmissão de uma tradição, mas à comunicação entre as gerações. Assim, verifica-se uma reconciliação efetiva dos homens com as suas experiências. Sem isso, o homem permanece heterônomo, apenas se comportando, repetindo o passado (MATOS, 1989, 31-58). A storytelling, o ato de narrar, em Arendt, estimula, então, não uma conduta, mas um pensamento autônomo, o exercício do juízo crítico.

O que faz, então, a imparcialidade situada crítica? Mais uma vez, a imaginação cumpre um papel fundamental. Sem ela, a experiência perde a sua dizibilidade, fica perdida no turbilhão das vivências e hábitos costumeiros. Na narração, a imaginação "sai em visita" de tal modo que o ouvinte/leitor é levado a situar-se em várias posições e estimulado a escolher ele próprio a própria posição. 0 storyteller não oferece a posição verdadeira, não resolve as ambiguidades e dilemas das situações, mas tenta pôr o leitor/ouvinte a par da experiência "estoriada" para que ele venha a parir os próprios pensamentos. A imparcialidade de Tucídides não se segura num padrão externo (Arquimedes), mas na atividade dialogante do eu consigo e com outros, no pensar sem cessar o que está ocorrendo. A criticidade dessa posição emerge justamente nesse movimentar-se da imaginação de posição para posição e somente quem está interessado em contar uma história pode abrir-se para as várias posições ${ }^{1}$, embora jamais consiga "visitar" todas elas e é isso que faz com que a história (history) nunca tenha um fim, pois jamais poderemos nos colocar totalmente fora dela e vê-la no seu todo. As várias "histórias" (stories) não podem ser submetidas a um padrão único, pois isso acarretaria a perda dos seus padrões inerentes, os seus sentidos próprios. Nesse aspecto, a imparcialidade situada mostra-se superior à imparcialidade abstrata, externa, pois mais capacitada para recuperar a singularidade das experiências sem cair no "calvário das abstrações" e na "alegorização universal" desrealizadores das coisas e pessoas, na qual cada pessoa e relação podem significar, a qualquer instante, outra coisa.

A criticidade, assim entendida, não pressupõe a abstração, um fundamento universal que, embora possa servir para legitimar uma ação, não instiga o pensar por conta própria - mas

1 "Pensar com a mentalidade alargada significa treinar a própria imaginação para sair em visita". (ARENDT, 1993b, p. 57). 
se realiza efetivamente na medida em que através de um distanciamento não absoluto, põe em circulação as várias perspectivas e "histórias" e, por isso, não pode funcionar como fundamento absoluto para um agir ou pensar, mas apenas estimular "fermenta cognitiones".

\section{Referências}

ARENDT. H. A Condição Humana. Trad. R. Raposo. Rio de Janeiro: Forense, 2010.

ARENDT, H. Lições sobre a Filosofia Política de Kant. Trad. A. Duarte. Rio de Janeiro: Relume/Dumará, 1993b. ARENDT, H. A Vida do Espírito. Trad. A. Abranches et al. Rio de Janeiro: Relume/Dumará, 1992.

ARENDT, H. Essays in Understanding. Ed. por Jeromy Kohn. Nova York: HB\&C, 1993a.

ARENDT, H. Homens em Tempos Sombrios. Trad. D. Bottmann. São Paulo: Companhia das Letras, 1987.

BENHABIB, S. Hannah Arendt and The Redemptive Power of Narrative. Social Reaseach, v. 57, n. 1, 1990, p. 167-196.

BENJAMIN, W. Obras Escolhidas. Vol. 1. Trad. S. Rouanet et al. São Paulo: Brasiliense, 1993.

DISCH, L. Hannah Arendt and the Limits of Philosophy. Nova York: Cornel University Press, 1996.

MATOS, O. Os Arcanos do Inteiramente Outro. São Paulo: Brasiliense, 1989.

MORAES, E. Filosofia e Política em Hannah Arendt. Perspectivas: Revista de Ciências Sociais, v. 16, 1993, p. 111-118.

RICOUER, P. Preface. In: ARENDT, H. Condition De L'homme Moderne. Paris: Calmann-Levy, 1995.

ROUANET, P. Édipo e o Anjo. Rio de Janeiro: Tempo Brasileiro, 1990.

Recebido em: $12 / 03 / 2021$

Aprovado em: 25/05/2021.

\section{Odilio Alves Aguiar}

Doutor em Filosofia pela Universidade de São Paulo - USP, Professor do Departamento de Filosofia da Universidade Federal do Ceará - UFC. 